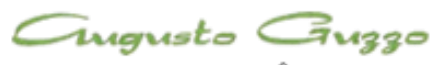

REVISTA ACADEMICA

\title{
A política educacional como instrumento da cidadania
}

\author{
Sérgio da Costa Bortolim
}

Recebido em: 03/10/2014. Aprovado em: 23/11/2014. Disponibilizado em: 26/12/2014

1. Sérgio da Costa Bortolim é Mestre em Políticas Sociais pela UNICSUL, Graduado em Filosofia e Especialista em Formação de Professores. É professor titular do Centro Paula Souza e coordena as áreas de filosofia e sociologia do Colégio Agostiniano São José, em São Paulo. Email: scbortolim@yahoo.com.

\section{Resumo}

A política é um exercício humano e se constrói no seio de uma coletividade. E a educação é a estrutura de execução da política hegemônica na atualidade que visa criar indivíduos dóceis a uma realidade de constante submissão e de empobrecimento econômico, cultural e moral. Cabe ao profissional da educação emancipar-se e promover a emancipação daqueles que sua profissão pode atingir, ou seja, toda a sociedade.

Palavras-chave: Política. Educação. Neoliberalismo. Docência.

\begin{abstract}
Politics is a human exercise and builds within a community. And education is the implementation structure of hegemonic politics today aimed at creating docile to a reality of constant submission and economic, cultural and moral impoverishment individuals. Up to the professional education to emancipate themselves and promote the emancipation of those who can reach their profession, ie, the entire society.
\end{abstract}

Keywords: Politics. Education. Neoliberalism. Teaching. 


\section{Introdução}

O processo político permeia toda esfera da vida humana e reconhecer esta extensão e não participar dela requer uma apatia frente ao conhecimento construído ao longo da história e, sobretudo, à própria vida humana.

Vale ressaltar que a formação humana não é dependente da formação escolar, todavia, é desta última que almejamos destacar como princípio norteador deste artigo e que possibilita a efetivação da história humana com seus contrastes, suas intencionalidades e suas rupturas frente aos paradigmas que priorizam os "preços" sobre os "valores". Eis que, no enfrentamento de ideias que a vida se efetiva. A vida muito além da esfera biológica, mas sim, da vida política.

Todo docente de qualquer sistema formativo é um agente político em potencial. Precisa se despertar para tal função, carece de treinamento político que, na própria prática do trabalho, é capaz de adquirir, embora tenha fortes pressões para que isso nunca ocorra, mas isso não invalida a procura por rupturas e novas visões de ser dignamente humano em uma realidade com ausências de perspectivas reais desta edificação da dignidade.

\footnotetext{
${ }^{1}$ Destacamos os fatos recentes nas relações internacionais no Oriente Médio, particularmente, na Tunísia, Síria e Egito, países que destituíram seus governantes depois de terem vivenciado um levante popular iniciado de maneira virtual e que tomou as ruas de suas principais cidades na luta pela democracia participativa. Evento que ficou conhecido como "Primavera Árabe".

2 Exemplos não faltam e variam da esfera pessoal/familiar como a luta pela união homoafetiva e pela possibilidade legal de adoção, perpassando pelo campo do trabalho, como a manutenção de direito à greve, à aposentadoria integral, dentre outros.
}

\section{Mas... o que é Política?}

Definir o termo "Política" na atual conjuntura mundial de rupturas de sistemas de governo geradas por conflitos impositores de democracias e as antagônicas tentativas de manutenção de regimes autocráticos ${ }^{1}$, luta por direitos ainda inexistentes e resgate de outros perdidos ${ }^{2}$, dentre outros fatores, requer um olhar cuidadoso sobre este conceito, em particular atenção, à política educacional brasileira. Antes, vejamos as possíveis definições que nos auxiliarão nesta reflexão.

Etimologicamente, o termo "política" advém do grego "politike (subentendido tekhne), arte ou ciência da cidade." (RUSS, 1994, p.220). Desta forma, associamos o termo política ao que se refere a "polis", àquilo que se relaciona à cidade ${ }^{3}$, sendo, portanto, o espaço público das relações entre os cidadãos. Conceitualmente, temos autores da antiguidade que esboçam uma análise sobre o termo aqui em questão, todavia é em Aristóteles, com a obra A Política, que essa discussão toma as proporções que almejamos destacar.

Para o pensador grego, a política está associada à cidade. É através dela que o homem desenvolve o bem maior que pode realizar. A cidade reconstrói vontades

\footnotetext{
${ }^{3}$ Cabe destacar que na Grécia Antiga, o conceito de pólis, tangia à definição de Cidade-Estado (núcleo urbano e rural que se mantinha de forma autônoma em relação a outras pólis com suas respectivas formas de governo e projetos educacionais. Exemplificação histórica, segundo Chauí, se dá à formação militar pela pólis espartana e a formação filosófico cultural pela pólis ateniense). Este espaço era organizado e formado pelos cidadãos, os quais eram homens, nascidos no território da pólis, possuidores de bens, livres. (CHAUÍ, 2010)
} 
individuais colocando-as a patamares inferiores à esfera da coletividade:

Sabemos que toda cidade é uma espécie de associação, e que toda associação se forma tendo por alvo algum bem; porque o homem só trabalha pelo que ele tem conta de um bem. Todas as sociedades, pois, se propõem qualquer lucro - sobretudo a mais importante delas, pois que visa a um bem maior, envolvendo todas as demais: a cidade política (ARISTÓTELES, 2006, p. 10).

A política em Aristóteles não se desvincula da esfera moral, de matriz axiológica. A política possui uma finalidade: possibilitar ao Estado o poder que permita aos indivíduos se edificarem como seres de virtude, ou seja, se instrumentalizarem como seres morais, tendo condições para sua prática. Desta forma, a política visa à coletividade dos indivíduos, não se relaciona unicamente à esfera individual. Por assim dizer, a Ética e a Política passam a ser conceitos distintos, todavia relacionais, pois a Ética está vinculada à doutrina moral do indivíduo, análise dos aspectos individuais, já a Política associa-se à doutrina moral social. Eis que, em Aristóteles, a Política é um exercício plenamente humano que, em seu contexto social, o remete a buscar aquilo que mais anseia: a felicidade, a eudaimonia. Para Marcondes (2007), o termo eudaimonia (ou felicidade) está associado ao bem-estar, que só é possível na busca do Bem, pela virtude.

O termo eudaimonia pode ser entendido também como bem-estar, principalmente como bem-estar em relação a algo que se realiza. Portanto, na concepção aristotélica a felicidade está relacionada à realização humana e ao sucesso naquilo que se pretende obter, o que só se dá se aquilo que se faz é bem feito, ou seja, corresponde a excelência humana e depende de uma virtude (areté) ou qualidade de caráter que torna possível essa realização (MARCONDES, 2007, p.40).
O homem é um ser existente para ser feliz, para a busca do bem-estar individual que implica sua coexistência aos interesses sociais, com as necessidades da cidade, enfim com a própria natureza da pólis. O homem é, pois, um animal político.

É evidente, pois, que a cidade faz parte das coisas da natureza, que o homem é naturalmente um animal político, destinado a viver em sociedade, e que aquele que, por instinto, e não porque qualquer circunstância o inibe, deixa de fazer parte de uma cidade, é um vil ou superior ao homem (ARISTÓTELES, 2006, p.12).

Por assim refletir, destacamos aqui que o conceito aristotélico de política nos fundamenta inicialmente, pois, compreendemos que a Política se configura como uma ação de realização do ser humano, em que o Bem Comum é um aspecto muito mais profundo do que o Bem Individual, haja vista que o anseio último do ser humano buscado em si mesmo e não em relação a outra coisa (a Felicidade) - só se concretizará na Pólis, que é o espaço coletivo dos indivíduos. Daí, portanto, que o homem só é capaz de se realizar plenamente na coletividade, ou seja, na pólis. E é nesta coletividade que os indivíduos são formados pelo processo educativo existente em cada época.

Sabe-se, ainda, que no pensamento aristotélico nenhum homem consegue ser virtuoso desarraigado da prática cotidiana. A virtude é a força do hábito e, desta forma, ser um bom cidadão requer um exercício diário que forme o próprio homem para aquilo que ele tem por finalidade: praticar o bem e ser feliz. E isso não é possível isoladamente, pois é através da relação com o outro, na cidade, nos desafios coletivos, que a felicidade pode ser 
construída de forma objetiva e intencionalizante. Segundo Aristóteles:

[...] de todas as coisas que nos vêm por natureza, primeiro recebemos a potência e só depois exteriorizamos a atividade. Isso fica bem claro no caso dos sentidos, pois não foi por ver ou ouvir repetidamente que adquirimos a visão e a audição, mas, pelo contrário, nós as tínhamos antes de começar a usá-las, e não foi por usá-las que passamos a tê-las. No entanto, com as virtudes dá-se exatamente o oposto: adquirimo-las pelo exercício [...] Efetivamente, as coisas que temos de aprender antes de poder fazê-las, aprendemo-las fazendo [...] do mesmo modo, tornamo-nos justos praticando atos justos, moderados agindo moderadamente, e igualmente com a coragem, etc. O que estamos dizendo é confirmado pelo que acontece com as Cidades-Estados: os legisladores tornam bons os cidadãos por meio de hábitos que lhes incutem. Esse é o propósito de todos os legisladores, e quem não consegue alcançar tal meta, falha no desempenho de sua missão, e é exatamente neste ponto que reside a diferença entre a boa e má constituição (ARISTÓTELES, 2001, p.40-41).

É nesta ótica da habitual prática de virtudes como condutora dos homens à vivência social virtuosa e que, na pólis, tornase instrumentalizadora da busca do Bem que orientamos nossa análise das políticas educacionais, especialmente, na intencionalidade da ação. A intencionalidade das ações políticas deve partir de uma prática cotidiana dos profissionais da educação em sala de aula. Se isso não ocorre, os professores falham em seu objetivo profissional, que aqui afirmamos ser um escopo, notoriamente, de politização dos discentes para a vivência no ambiente social, com todos os emblemáticos desafios decorridos das relações interpessoais e dicotomias econômicas, tendo por atuação (ainda em um conceito aristotélico) ser amigo do discente, pois a amizade é uma disposição do caráter, é intencional, proposital em vista do bem comum (bem-estar, felicidade). Para ser amigo é necessário a convivência, o tempo e a intimidade que, no caso docente, apresenta-se no ambiente escolar (na sala de aula ou fora dela).

[...] Até em nossas viagens podemos observar a formação de uma afinidade e afeição entre as pessoas. A amizade também parece manter as cidades unidas, e dir-se-ia que os legisladores preocupam-se mais com a amizade do que com a justiça, pois buscam assegurar acima de tudo a unanimidade, que parece assemelhar-se à amizade, ao mesmo tempo em que repelem o facciosismo, que é o maior inimigo das cidades. Quando os homens são amigos não necessitam de justiça, ao passo que mesmo os justos necessitam também da amizade; e considera-se que a mais autêntica forma de justiça é uma espécie de amizade (ARISTÓTELES, 2001, p.172-173).

Desta forma, o professor educa para a amizade, no intuito de, com o outro, melhorar a si mesmo, ou seja, na relação com o aluno, ensinando-lhe a prática da cidadania (aqui entendida como a prática do Bem), facilitando o estímulo à amizade ao discente, e ambos, ao exercitá-la, também se praticará a justiça, que é característica do cidadão, possibilitando o retorno positivo de sua ação à sua própria vida, transcendendo o espaço estritamente profissional do território escolar.

$\mathrm{Na}$ história da educação, especificamente na Grécia Antiga, Aristóteles criticava a educação espartana, que ostentava a guerra, a competição do mais forte, como processo formativo dos indivíduos, em detrimento ao que deveria ser a formação dos indivíduos: uma formação embasada nas artes, na filosofia, enfim para uma pacífica formação científica e moral. Eis que, disso, surge uma indagação central: sob qual ótica 
política estão sendo formados os indivíduos na sociedade do século XXI? Quais as ideologias políticas que permeiam as práticas pedagógicas dos professores na contemporaneidade? Qual a conjectura que se estabelece institucionalmente com a anuência dos povos (ou submissão destes)? Como ressignificar a ideia aristotélica de que a política é um exercício do cidadão? A que cidadão nos referimos na atualidade? Quais hábitos estão sendo cultivados na prática educacional?

\section{As Políticas Neoliberais: a \\ hegemonia econômica e as necessidades sociais.}

Compreende-se aqui o neoliberalismo como sendo o modelo político-econômicocultural hegemônico no período de declínio do século XX (após a década de 1970) até nossos dias. Usufrui do processo de globalização para transpor territórios, antes permeados por doutrinas sociais, e que, agora, se abrem ou compactuam com os interesses do capital especulativo, também chamado de neoliberalismo de mercado, que contrasta com as políticas de Bem-Estar social.

Historicamente, após a Segunda Guerra Mundial (1939-1945), o planeta presenciou o

\footnotetext{
4 “Fisiocratas. Economistas europeus do século XVIII que combateram as ideias mercantilistas, sistematizando a teoria do liberalismo econômico. Lançaram a célebre máxima do liberalismo: laissezfaire, laissez-passer ("deixa fazer, deixa passar"). E propuseram a supressão de todas as taxas, com sua substituição por um imposto único incidindo sobre a propriedade, já que esta seria a única fonte de riqueza e os proprietários apenas se apropriam da renda da terra sem contribuir para o aumento do produto líquido, enquanto os agricultores, os comerciantes e os artesãos deveriam ficar aliviados da carga tributária para que se facilitasse a circulação da renda. Para manter essa ordem
}

conflito ideológico entre os Estados Unidos da América (EUA) e a União das Repúblicas Socialistas Soviéticas (URSS). Este confronto caracterizou-se pelas corridas armamentista, espacial, tecnológica, entre outros, além de a criação de pactos financeiros de apoio aos países devastados pelos conflitos bélicos anteriores a 1945. Segundo Ianni (1999), começou a ocorrer um novo desenvolvimento da realidade social, na qual a produção é intensificada e generalizada, instituindo-se o processo de globalização que "Trata-se de uma formação social global, desigual e problemática, mas global; [...] que com o consumismo sem medidas muda completamente o que se espera e o comportamento das pessoas" (IANNI, 1999, p. 43).

Conceitualmente, o neoliberalismo estabeleceu uma retomada do pensamento da Escola Fisiocrata ${ }^{4}$ sugestionando uma nova forma de pensar a questão da liberdade, partindo da globalização econômica, embasada no consumo de bens e serviços diversos, dentre eles, a própria educação.

Este processo neoliberal teve sua fundamentação inicial com Friedrich A. Hayek e estava baseada em dois fatos principais: primeiro, a publicação de sua obra "O Caminho da Servidão", em 1944, e, posteriormente, a criação do grupo internacional The Mont Pèlerin Society ${ }^{5}$,

natural, o Estado deveria assumir o papel exclusivo de guardião da propriedade e garantidor da liberdade econômica". (SANDRONI, 1987, p.173). 5 Penna (1999) descreve a Sociedade de Mont Pèlerin, fundada na Suíça, foi uma convocação de Friedrich A. Hayek para os célebres personagens compartilhadores de sua teoria. Nesta seleta assistência encontravam-se Milton Friedman, Karl Popper, Lionel Robbins, Ludwig von Mises (do qual Hayek era discípulo), Walter Eupken, Michael Polnyi, dentre outros. Esta sociedade caracterizava-se como uma espécie de francomaçonaria neoliberal, altamente dedicada e organizada com reuniões internacionais bienais. 
fundado por ele, em 1947. Estes fatos reforçaram a adversidade em relação ao Estado de Bem-Estar e/ou a inimizade do New Deal norte-americano ${ }^{6}$, prevendo uma profunda crise do capitalismo, se mantida a estrutura social apoiada no keynesianismo.

Essa crítica ao Estado de Bem-Estar Social - para muitos, originalmente "culpado" da crise da década de 1970, também foi observada por outros autores. Grassi (1994) investiga a crítica conservadora (neoliberal) ao modelo do Estado regulador de redistribuição de recursos e de regulação econômica. Para ela:

La "crisis de acumulación encontró
rápidamente, vía el discurso neoconservador
que logró hegemonizar el campo político-
cultural, um "culpable": el Estado de
Bienestar y su papel em la redistribución de
recursos y em la regulación de la economia.
Esta "crítica conservadora" al Estado de
Bienestar ganó rápido consenso y la
desregulación económica y la reducción de los
gastos fiscales, pasaron a ser los prerequisitos
de las politicas restauradoras de las tasas de
ganancia; requisito, a su vez, de la "superación
de la crisis" (GRASSI, 1994, p.116-117).

Este processo neoliberal se desenvolveu, especificamente, após 1973, com a crise econômica mundial que promoveu, especialmente nos países de base capitalista, recessão profunda e elevada inflação. Particularmente, a crise do petróleo, ocasionou o fenômeno do desemprego em

Protagonizava o propósito de combate ao keynesianismo e ao solidarismo reinantes e o preparo das bases de outro tipo de capitalismo, duro e livre de regras para o futuro.

${ }^{6}$ New Deal - programa econômico (1933) adotado pelo presidente americano $\mathrm{F}$. Roosevelt para combater os efeitos da grande depressão e refazer a propriedade do país. Seguiu a teoria de Keynes: baseou a intervenção do Estado no processo produtivo, com o objetivo de atingir o pleno emprego, o que contradizia toda a tradição liberal dos EUA. (SANDRONI, 1987, p. 245) massa, possibilitando a tendência de contrariar as doutrinas keynesianas ${ }^{7}$, as quais propunham uma atuação do Estado sobre a economia de forma a apoiar o sistema capitalista em seu desenvolvimento, todavia gerando um Estado de Bem-Estar Social.

Cabe ressaltar que as releituras do liberalismo econômico iluminista perfazem duas grandes leituras no século XX, a saber: o social-liberalismo, proposto por Keynes (após a Crise de 1929), e o neoliberalismo, proposto por Hayek. Em ambos os casos temos uma interpretação tendenciadora a um retorno à raiz clássica, todavia entre elas têmse um diferencial, sobretudo, no que tange à esfera paradigmática de rigidez de aplicação da teoria clássica. Libâneo (2006) esclarece estas duas macrotendências do capitalismo/liberalismo do século XX:

É possível notar que essas duas perspectivas se opõem na adoção de ações políticas, econômicas, sociais e culturais, para obter hegemonia na condução de um projeto de modernização capitalista. A primeira tendência, o novo liberalismo/socialliberalismo que tem J.Dewey (18581952) e M.Keynes (1883-1946) como maiores expoentes, assume a hegemonia ideológica na sociedade capitalista da Segunda Guerra Mundial até a primeira metade da década de 70 , quando então começa a se esgotar. A segunda, o neoliberalismo de mercado

\footnotetext{
${ }^{7}$ Keynesianismo $=$ Teoria fundamentada por John Maynard Keynes (1883-1946) economista inglês, o qual elaborou o suporte teórico para o Estado de Bem-Estar Social. Publica a obra Teoria geral do emprego, do lucro e da moeda (1936) recomendando, devido a crise capitalista após a Grande Depressão de 1929, a intervenção do Estado na economia. Este, através de investimentos públicos, deveria garantir os direitos sociais como transporte, saúde, seguro social, educação, habitação, etc. Desta forma, se evitaria os surgimento das crises cíclicas do capitalismo. Cf. RODRIGUES (1995).
} 
(conservador e elitista), cujo maior expoente é F.A.Hayek, sai de seu estado de hibernação para dar novo fôlego e soluções à crise mundial da década de 70 , alcançando seu ponto mais alto nos governos de Ronald Reagan (EUA) e Margaret Thatcher (Inglaterra) (LIBÂNEO, 2006, p.86).

A dicotomia entre as propostas neoliberais e social-liberais trouxe uma vasta bibliografia sobre o tema. De qualquer forma, em ambas, vemos um jogo ganho de um único modelo econômico mais ou menos distributivo das riquezas socialmente produzidas.
Diante de contextos de crise, os modelos econômicos em destaque propuseram projetos de modernização em diversas áreas. Atualmente, vemos no Brasil uma construção histórica da presença do Estado cada vez mais influente nas decisões econômicas. No entanto, as influências continuam a se limitar à manutenção dos privilégios do mercado, sob o controle de monopólios, em relação às inúmeras necessidades sociais de um país marcado pela escravidão e tantas outras condições desiguais enraizadas historicamente.

A tabela a seguir explana estes projetos propostos pelas macrotendências econômicas:

Figura 1: Projetos de Modernização de Macrotendências Econômicas. (Adaptado de: LIBÂNEO, 2006: 88-89).

\begin{tabular}{|c|c|}
\hline \multicolumn{2}{|c|}{ LIBERALISMO/CAPITALISMO (Projetos de Modernização) } \\
\hline $\begin{array}{c}\text { Social-Liberalismo/Novo liberalismo } \\
\text { (KEYNES) }\end{array}$ & Neoliberalismo de Mercado \\
\hline $\begin{array}{l}\text { Paradigma da igualdade de oportunidades. } \\
\text { Tendência capital-liberal estatizante e } \\
\text { democrática que imprime um projeto de } \\
\text { modernização caracterizado por: }\end{array}$ & $\begin{array}{l}\text { Paradigma da liberdade econômica, da eficiência e } \\
\text { da qualidade. } \\
\text { Tendência capital-liberal concorrencial e elitista- } \\
\text { conservadora que imprime o seguinte projeto: }\end{array}$ \\
\hline \multicolumn{2}{|c|}{ ECONOMIA } \\
\hline $\begin{array}{l}\text { Economia de mercado planejada e administrada } \\
\text { pelo Estado; economia mais coletivista/socializada; }\end{array}$ & $\begin{array}{l}\text { Economia de mercado autorregulável: livre } \\
\text { concorrência; fortalecimento da iniciativa privada } \\
\text { com ênfase na competitividade. }\end{array}$ \\
\hline \multicolumn{2}{|c|}{ ESTADO } \\
\hline $\begin{array}{l}\text { Estado de Bem-Estar Social: interventor, regulador, } \\
\text { organizador e planejador da economia; provedor do } \\
\text { pleno emprego e do crescimento da educação, da } \\
\text { saúde, da assistência aos desempregados, etc. }\end{array}$ & $\begin{array}{l}\text { Estado minimalista, com três funções: } \\
\text { policiamento, justiça e defesa nacional; projeto de } \\
\text { desestatização, desregulamentação e privatização; } \\
\text { desqualificação; desqualificação dos serviços e } \\
\text { políticas públicas. }\end{array}$ \\
\hline \multicolumn{2}{|c|}{ EDUCAÇÃO } \\
\hline $\begin{array}{l}\text { Ênfase na escola única, pública, gratuita, laica, } \\
\text { universal e obrigatória; democrático-popular; } \\
\text { formação para a cidadania; planificação dos } \\
\text { sistemas de ensino. }\end{array}$ & $\begin{array}{l}\text { Ênfase no ensino privado, na escola } \\
\text { diferenciada/dual e na formação das elites } \\
\text { intelectuais; formação para o atendimento das } \\
\text { demandas/exigências do mercado. }\end{array}$ \\
\hline \multicolumn{2}{|c|}{ SELEÇÃO DOS INDIVÍDUOS } \\
\hline $\begin{array}{l}\text { Seleção das capacidades baseadas em critérios } \\
\text { naturais de aptidão e de inteligência; } \\
\text { desenvolvimento igualitário. }\end{array}$ & $\begin{array}{l}\text { Seleção dos melhores, baseada em critérios } \\
\text { naturais de aptidão e de inteligência; elitismo } \\
\text { psicocultural (seletividade meritocrática). }\end{array}$ \\
\hline
\end{tabular}

Fonte: produzida pelo autor em São Paulo SP, 2014. 
Dialogicamente, em relação ao mesmo tema, nos esclarece Höfling (2001), que o sistema neoliberal hayekiano de economia de mercado se contrapunha às teorias intervencionistas justamente na concepção da não intervenção do Estado na economia. Desta forma, o Estado deveria ser mínimo e o Mercado deveria ocupar-se de regular a economia e todos os demais setores da sociedade, dentre eles, podemos incluir o próprio sistema educacional.

As teses neoliberais, absorvendo o movimento e as transformações da história do capitalismo, retomam as teses clássicas do liberalismo e resumem na conhecida expressão "menos Estado e mais mercado" sua concepção de Estado e de governo. Voltadas fundamentalmente para a crítica às teses de Keynes (1883-1946), que inspiraram o Estado de Bem-Estar Social, defendem enfaticamente as liberdades individuais, criticam a intervenção estatal e elogiam as virtudes reguladoras do mercado. Estas ideias ganharam força e visibilidade com a grande crise do capitalismo na década de 1970, elas foram apresentadas como possíveis saídas para as mesmas. (HÖFLING, 2001, p.36).

Estas relações socioeconômicas, embasadas na teoria hayekiana, geraram uma forte tendência de exploração exacerbada da força de trabalho, favorecendo relações sociais e contratuais bem mais flexíveis, imprimindo uma pressão sobre os sindicatos e ampliando a perda do poder dos trabalhadores e a diminuição de direitos sociais conquistados até então. Para Comblin (1999):

Por sinal, a sindicalização torna-se cada vez mais difícil e impopular. Existem muitas técnicas de relações humanas inspiradas pela psicologia ou pela sociologia do trabalho, que facilitam a integração do trabalhador na empresa, desestimulam todos os conflitos e desanimam qualquer espírito de contestação. As novas leis sociais procuram deixar o trabalhador sozinho frente à empresa, e estas destroem o sistema da convenção coletiva do trabalho. (COMBLIN, 1999, p.29).

Estas características globais baseadas em medidas governamentais que integram as políticas neoliberais - que atualmente estão sendo reaplicadas em países europeus no póscrise econômica de 2008, gerando fortes protestos de mobilização popular - estavam focadas na precarização do trabalho, na informalidade de atividades, no desemprego estrutural, todavia estavam ideologicamente revestidas de um valor simbólico em que a competição era tratada como o método mais digno de despertar as potencialidades humanas, do ponto de vista individual. Segundo o pai do neoliberalismo:

A argumentação liberal propugna pelo melhor uso possível das forças de competição como um meio de coordenar os esforços humanos, e não pretende que as coisas devam ser deixadas como estão. Baseia-se na convicção de que, onde se puder criar uma efetiva concorrência, aí se terá a melhor maneira de guiar os esforços individuais (HAYEK, 1977, p. 35).

Este processo competitivo, concorrencial para desenvolvimento das potencialidades humanas, é visto por Dupas (1999), como um modelo modificador da sociedade mais do que a esfera econômica; é um instrumento que reestrutura as identidades e incentiva a redefinição dos valores em que as pessoas baseavam suas vidas, promovendo de forma intensiva a competição em detrimento à solidariedade e a aceitação das realidades díspares de acumulação de capital em oposição aos investimentos sociais. Para ele: 
A reestruturação econômica, a liberalização, as mudanças tecnológicas e a competição feroz que acompanham a globalização, tanto no mercado de bens quanto nos de mão de obra, contribuíram para aumentar o empobrecimento, as desigualdades, a insegurança no trabalho, o enfraquecimento das instituições, dos sistemas de apoio social, o desgaste das identidades e dos valores estabelecidos (DUPAS, 1999, p.72).

Se estas transformações neoliberais possuem a potência axiológica de um enfoque na mudança de valores arraigado ao consumismo, elas também partem do pressuposto de que o ser humano é um ser dotado de desejos constantes e infindáveis, e que cada um é livre para satisfazê-los, logo o mercado deveria se sustentar nesta mesma liberdade no estabelecimento de suas próprias regras. Assim, ressignifica-se a teoria fisiocrata, de Adam Smith, da mão invisível do mercado: o mercado é livre para produzir e o indivíduo é livre para consumir, indistintivamente. $\mathrm{O}$ foco está em suprir suas necessidades, mesmo que o foco esteja unicamente no plano individual. É o preenchimento das lacunas deixadas pelo anseio da felicidade volátil. É o amadurecimento do valor da liberdade fragmentada, superficial, de cunho estritamente econômico.

Höfling (2001) revela o caráter contraditório do neoliberalismo. Para a autora, quando o neoliberalismo combate as políticas do Estado de Bem-Estar Social, ele está deixando de reconhecer as consequências de suas imposições econômicas, pois os desequilíbrios crescentes precisam ser superados para o desenvolvimento da sociedade que deveria buscar a realização dos indivíduos para que todos, em suas diversas atividades possam se realizar em prol da felicidade que, mesmo sendo individual, se realiza plenamente na esfera social.
Para os neoliberais, as políticas (públicas) sociais - ações do Estado na tentativa de regular os desequilíbrios gerados pelo desenvolvimento da acumulação capitalista - são consideradas um dos maiores entraves a este mesmo desenvolvimento e responsáveis, em grande medida, pela crise que atravessa a sociedade. A intervenção do Estado constituiria uma ameaça aos interesses e liberdades individuais, inibindo a livre iniciativa, a concorrência privada, e podendo bloquear os mecanismos que o próprio mercado é capaz de gerar com vistas a restabelecer o seu equilíbrio. Uma vez mais, o livre mercado é apontado pelos neoliberais como o grande equalizador das relações entre os indivíduos e das oportunidades na estrutura ocupacional da sociedade (HÖFLING, 2001, p.37).

Eis que, no jogo do poder, que na Grécia Antiga - de embasamento aristotélico - se mantinha no Estado a manutenção dos interesses dos cidadãos em prol da felicidade social, agora se evidencia no mercado financeiro o controle dos interesses e dos anseios possíveis dos indivíduos, os quais precisam se adequar ao modelo vigente para suprir suas constantes necessidades (cada vez maiores). A competição passa a ser sinal de sobrevivência, especialmente para as empresas. Aquelas que desenvolvem bem sua logística investem em tecnologia ou mesmo por possuírem outras influências políticas deterão o micropoder aplicado na satisfação de suas necessidades e possibilitando as empresas de grande porte, principalmente o monopólio, em seus respectivos setores produtivas.

Esta prática é fundamentada por Hayek (1977) ao afirma que "Segundo as regras do jogo concedidas, o indivíduo é livre para perseguir suas metas e desejos pessoais, tendo a certeza de que os poderes do governo não serão empregados no propósito deliberado de malograr seus esforços.” (p.70). É a defesa do livre comércio, desde que essa liberdade 
esteja vinculada a um favorecimento de interesses a determinados grupos. Este método de incentivo ao monopólio empresarial e à concomitante diminuição de investimentos sociais por parte do Estado salvaguarda a recuperação de empresas/indústrias de grande porte e/ou blocos econômicos. Fatos recentes mais evidentes após crise de 2008 são as ações governamentais em diversas localidades. Dois exemplos: a) na Europa, a União Europeia viabilizou à Grécia $€ 130$ bilhões no primeiro semestre de 2012, como empréstimo para que ela possa repor pagamentos atrasados a credores, afastando de forma muito breve o desespero de um país imerso em um colapso econômico que já afeta o enfraquecimento do bloco econômico europeu; b) já no Brasil, tivemos as reduções de IPIs (Impostos sobre Produtos Industrializados), especialmente, sobre o setor automotivo, apoiando o consumo deste respectivo setor.

Dentre os exemplos deste fenômeno político-econômico destacam-se o FMI (Fundo Monetário Internacional) e o Banco Mundial como financiadores de políticas públicas em todo o mundo, espalhando o novo pensamento neoliberal. Sobre este último, identifica Libâneo (2006):

As orientações do Banco Mundial para o ensino básico e superior são extremamente representativas deste novo momento. Elas refletem a tendência da nova ordem econômica mundial, o avanço das tecnologias e da globalização [...]. No entanto, o banco também estimula o aumento da competitividade, a descentralização e a privatização do ensino, eliminando a gratuidade (sobretudo nas universidades públicas) [...] O Banco Mundial requer que a educação escolar esteja articulada ao novo paradigma produtivo $[\ldots]$. É necessário que a educação, a capacitação e a investigação avancem em direção a um enfoque sistêmico. (LIBÂNEO, 2006, p.102103).

O sistema neoliberal, além de atingir os campos político e econômico - que são seus 'rótulos' mais conhecidos -, ele também é um sistema global e filosófico que busca absorver todas as esferas da vida humana, dentre elas: a educação. Esta esfera é estratégica por dois motivos: para atender aos objetivos da produção capitalista, ao preparar os trabalhadores com uma visão estritamente tecnológica; e também para difundir a cultura liberal, como única maneira de desenvolvimento das liberdades de iniciativa e de mercado (AHLERT, 2003).

O interessante é que a política deste Estado neoliberal que defende o interesse de alguns quer fazer-se passar pela voz de todos. $\mathrm{Na}$ compreensão de Janete de Azevedo (2004), o Estado capitalista, mesmo não sendo, apresenta-se como representante do "interesse geral" de grupos distintos: ele é simultaneamente o Estado popular, racional e de classe. Para a autora, o Estado:

O Estado [...] comporta [...] um jogo de força que permite o reconhecimento dos interesses do trabalho, dentro de determinados limites. Tudo depende da estratégia acionada pela dominação hegemônica das classes dominantes, em busca do "consentimento". A noção de interesse do "povo", apesar de ideológica, implica que sejam atendidos determinados interesses econômicos de certas classes dominadas, mesmo que esses interesses, eventualmente, contrariem os interesses econômicos predominantes [...] (AZEVEDO, 2004, p.45).

A metodologia do neoliberalismo foi aplicada também à educação por meio de legislações, de cursos de formação de professores, de formação do currículo dos cursos de licenciatura. Além disso, houve o aviltamento das políticas educacionais através do achatamento salarial dos professores, do 
aumento da quantidade de alunos em sala de aula. Os professores, dessa forma, são forçados a ficarem submissos à degradação da qualidade de seu trabalho, tendo em vista que a valorização do exercício docente é considerada, unicamente, para fins de promessas eleitorais dos diversos partidos políticos. Em contrapartida, na prática, a realidade é rechaçada sob o argumento de falta de verbas ou, no caso das empresas privadas, há a elevação da carga horária de trabalho (presencial e online) sem o aumento salarial correspondente.

Cabe salientar que por mais que as instituições privadas de ensino sejam autônomas em suas organizações institucionais, todas elas estão diretamente subordinadas a legislações emergidas da esfera pública, sendo tratada aqui, a educação nos sistemas públicos quanto privados, como resultado de políticas públicas de educação.

Eis que essa ótica neoliberal perfaz a lógica educacional constituindo uma cultura comercializada e comercializadora, de tal forma que os indivíduos a ela pertencentes se valham deste "projeto civilizacional" de raiz moral individualista. Para Ball (2001), esta realidade é muito bem apresentada, na qual ele associa a vinculação de um modelo único de formação ideológica nas instituições de ensino calcado no paradigma comercial que relaciona o interesse público ao privado. Neste sentido, utilizando-se do pensamento de Benton (1992), coloca: "O novo quadro de políticas, em geral, e a forma do mercado, em particular, constituem o novo ambiente moral tanto para consumidores quanto para produtores - ou seja, uma forma de “civilização comercial”" (BENTON, 1992, p.118 apud BALL, 2001, p.106).

Nessa mesma direção e apoiado em Planton (1992), acrescenta: "No seio deste novo ambiente moral, as escolas e as universidades são induzidas a uma 'cultura de autointeresse”" (PLANT, 1992, p. 87 apud
BALL, 2001, p.106). Esta é uma relação que tende a impulsionar a utilização do espaço público pelo interesse privado, atrelando, de forma reducionista, os interesses da educação aos interesses empresariais. Ball (2001) afirma:

As motivações pessoais sobrepõem-se aos valores impessoais. Os "procedimentos de motivação" inseridos neste novo paradigma de gestão pública elicitam e geram os impulsos, relações e valores que fundamentam o comportamento competitivo e a luta pela vantagem. Assim, aquilo que temos assistido, através da celebração da competição e da disseminação de seus valores na educação, é a criação de um novo currículo ético nas e para as escolas e o estabelecimento de uma "correspondência" moral entre o provimento público e empresarial. (BALL, 2001, p.106-107).

Este processo neoliberal que condiciona a educação a uma política de mercado, relativizada por indicadores de ensino, marketing para elevação do número de estudantes matriculados e outros difusores midiáticos, não aplica diretamente, o discurso do livre mercado, mas prepara as condições de sua existência para um melhor desenvolvimento do sistema neoliberal. Desta forma, Ball (2001), alerta que as instituições de mercado produzem as condições de florescimento da mentalidade do egoísmo humano e a competição natural entre os indivíduos. Assim, ele referencia-se ao pensamento de Bottery (1992), afirmando:

As economias de mercado livre baseiam-se em duas premissas. A primeira "é que o mercado, e por sua vez a competição entre as pessoas, é natural à condição humana". A segunda "é que a humanidade é composta por indivíduos que, em essência, são egoístas. Assim, o mercado apenas dá expressão a uma necessidade básica" 
(BOTTERY, 1992, p. 86 apud BALL, 2001, p.108).

As condições ora citadas estão imbricadas ao processo educacional, haja vista que a formação de mentalidades é influenciada pelo teor das políticas públicas de educação que, pelo discurso dos educadores e pelo ritmo das instituições, viabilizam a manutenção da cultura hegemônica, no caso neoliberal, competitiva e autodestrutiva. Todavia, cabe salientar que o processo educativo tendenciona a essa mentalidade, mas não se pode assumir uma postura determinista diante desse fato, pois as mesmas políticas que favorecem ao modelo neoliberal podem ser refutadas e utilizadas em um sentido antagônico ao almejado pelo sistema.

Isto se deve pela intencionalidade produtiva do professor que, como ser político que é, pode transcender aos condicionamentos sociais através de uma prática pedagógica que explique este processo ao aluno, possibilitando-lhe as reais condições da liberdade, se desvinculando da "cegueira política" e capacitando-o a escolher o próprio caminho, todavia vinculado a uma nova rede compartilhada, a saber: a rede da cidadania, da política, da vida enraizada para a coletividade, que transpõe aos interesses do individualismo e do permissivismo competitivo atuantes no modelo hegemônico.

É neste olhar sobre o papel do professor, que tem por missão fugir do reducionismo crítico que a economia vigente lhe tem por pretensão impor, que esta pesquisa focará mais adiante.

\section{Considerações Finais}

O pensamento neoliberal é um tipo de antítese dialética de uma política social. A intervenção do Estado no campo econômico torna-se sinônimo de "pecado mortal" que deve ser combatido pelos "fiéis mais devotos". E, especificamente, no campo educacional há um tratamento peculiar, diferente das demais políticas sociais, haja vista o caráter necessário para a formação da mão de obra para o sistema do trabalho na sociedade.

Esta lógica que afeta as políticas sociais também abrange a esfera educacional numa pseudo valorização do trabalho docente. A concepção que aqui temos é de que o trabalho é capaz de reestruturar uma sociedade. Especificamente, quando o trabalho pedagógico fomenta a formação da mentalidade cidadã aos discentes em detrimento às características do sistema hegemônico contemporâneo. Concebido assim, assumimos como premissa que o trabalho pedagógico de uma instituição de ensino é, prioritariamente, instigado pelo ofício docente. O professor atua, enquanto um ser político, para um fim social e, através de sua práxis, é produtor de conhecimento sobre a realidade vivenciada em seu respectivo contexto. Desta forma, o trabalho docente é um trabalho em prol de uma política social, sempre desafiadora, nova e inquietante em prol do coletivo em uma sociedade que reprime os discursos humanos e pratica, no seio da estrutura hegemônica, um modelo desumano para os humanos que ainda resistem ao sistema vigente.

\section{Bibliografía}

1. ABREU, Gilberto Andrade. A deserção da história: o pós-modernismo e o neoliberalismo como armas ideológicas do capitalismo global: um mal estar mais que uma ruptura. 2009. Tese (Doutorado)Universidade Estadual de Campinas, Campinas, 2009. 
2. AHLERT, Alvori. Políticas públicas e educação na construção de uma cidadania participativa, no contexto do debate sobre ciência e tecnologia. Revista da Educação, Umuruama, v.3, n.2, jul./dez. 2003.

3. ARISTÓTELES. A política. Trad. Nestor Silveira Chaves. São Paulo: Escala Educacional, 2006. (Série filosofar).

4. . Ética a Nicômaco. Trad. Pietro

Nassetti. São Paulo: Martin Claret, 2001.

5. AZEVEDO, Janete M Lins. A educação como política pública. 3. ed. Campinas: Autores Associados, 2004.

6. BALL, Stephen J. Diretrizes políticas globais e relações políticas locais em educação. Revista Currículo sem Fronteiras, v. 1, n. 2, p. 99-116, jul./dez. 2001.

7. COMBLIN, José. O neoliberalismo: ideologia dominante na virada do século. 2. ed. Petrópolis: Vozes, 2000.

8. DUPAS, Gilberto. Economia global e exclusão social: pobreza, emprego, estado e o futuro do capitalismo. São Paulo: Paz e Terra, 1999.

9. GRASSI, Estela. Neoliberalismo conservador y estado assistencialista: reflexiones críticas sobre los alcances y resolución de la crisis. Revista Serviço Social \& Sociedade, São Paulo, v. 15, n. 44, abr. 1994.
10. HAYEK, Friedrich A. O caminho da servidão. 2. ed. Tradução Leonel Vallandro. São Paulo: Globo, 1977.

11. HOFLING, Eloisa de Mattos. Estado e políticas (públicas) sociais. Cad. CEDES, Campinas, v. 21, n. 55, nov. 2001. Disponível em: <http://www.scielo.br/scielo.php? script $=$ sci_arttext\&pid=S0101$32622001000300003 \& \operatorname{lng}=$ en\&nrm $=$ iso $>$. Acesso em: 10 ago. 2014.

12. IANNI, Octavio. Teorias da globalização. Rio de Janeiro: Civilização Brasileira, 1999. 13. LIBÂNEO, José Carlos; OLIVEIRA, João Ferreira; TOSCHI, Mirza Seabra. Educação escolar: políticas estrutura e organização. 3. ed. São Paulo: Cortez, 2006. (Coleção docência em formação; Série saberes pedagógicos).

14. MARCONDES, Danilo. Textos básicos de ética. Rio de Janeiro: Jorge Zahar, 2007. 15. PENNA, J. O. M. A sociedade de Mont Pèlerin. Jornal da Tarde, 29 nov.1999. 16. RODRIGUES, Alberto Tosi. Gênese, retórica e prática. Campinas, maio/jun.1995. Disponível em: <http://www.cefetsp.br/ edu/eso/globalizacao/genesepratica.html>. Acesso em: 10 ago. 2014.

17. RUSS, Jacqueline. Dicionário de filosofia. São Paulo: Scipione, 1994.

18. SANDRONI, Paulo. Dicionário de economia. São Paulo: Editora Best Seller, 1987. (Coleção os Economistas) 